\title{
PERLINDUNGAN HUKUM PEKERJA KONTRAK DAN PEKERJA HARIAN DI PERHOTELAN KABUPATEN BADUNG *
}

\author{
Oleh : \\ I Komang Yudiastawan** \\ Ni Putu Purwanti *** \\ Program Kekhususan Hukum Bisnis \\ Fakultas Hukum Universitas Udayana
}

\begin{abstract}
ABSTRAK
Jurnal yang berjudul "Perlindungan Hukum Pekerja Kontrak dan Pekerja Harian di Perhotelan Kabupaten Badung" Dalam tulisan ini membahas tentang perlindungan hukum terhadap upah pekerja kontrak dan pekerja harian yang berkaitan dengan tidak terpenuhi hak karyawan tersebut. Menurut Keputusan Menteri Tenaga kerja dan Transmigrasi No.100/MEN/IV/2004 tentang Pelaksanaan Perjanjian Kerja Waktu Tertentu yang mengatur pekerja kontrak dan pekerja harian harus mendapat perlindungan ekonomis, sosial dan teknis. Salah satu perlindungan hukum yang menjadi perhatian penulis adalah perlindungan hukum terhadap upah pekerja kontrak dan pekerja harian. Metode yang digunakan dalam penulisan jurnal ini menggunakan penelitian hukum empiris, penelitian yang dilakukan dengan wawancara atau penelitian dengan secara langsung terjun kelapangan guna untuk mendapatkan kebenaran yang akurat dalam penulisan jurnal ini. Jenis pendekatan yang digunakan dalam penelitian ini adalah pendekatan perundangundangan (The Statue Approach) dan pendekatan analisis dan konsep hukum (Analytical And Conceptual Approach). Hasil dari studi menunjukan bahwa pelaksanaan ketentuan hukum yang berkaitan dengan perlindungan hukum upah minimum bagi pekerja kontrak dan pekerja harian belum terlaksana secara maksimal khususnya yang berkaitan dengan hak cuti yang tidak dibayarkan secara penuh. Pengaturan sanksi hukum bagi perusahaan perhotelan yang tidak menerapkan upah minimum terhadap pekerja kontrak dan pekerja harian adalah penuntutan dari pihak karyawan pekerja kontrak dengan cara pengajuan gugatan hubungan
\end{abstract}

\footnotetext{
* Makalah ini disarikan dan dikembangkan lebih lanjut oleh skripsi yang ditulis oleh penulis

** I Komang Yudiastawan adalah Mahasiswa Fakultas Hukum Universitas Udayana. Korespondensi: ast.yudi@gmail.com

${ }^{* * *}$ Ni Putu Purwanti adalah Dosen Fakultas Hukum Universitas Udayana
} 
industrial. Jurnal ini memberikan saran agar perusahaan yang mempekerjakan pekerja kontrak dan pekerja harian lebih meningkatkan perlindungan hukumnya termasuk pemenuhan hak cutinya. Perusahaan yang memperkerjakan pekerja kontrak dan pekerja harian secara bersikenambungan harus melakukan sosialisasi kepada karyawan pekerja kontrak dan pekerja harian berkaitan dengan hak-hak dan kewajibannya.

Kata kunci : Perlindungan Hukum, Pekerja Kontrak, Pekerja Harian

\begin{abstract}
This journal entitled "Legal Protection for Contract Employees and Daily Workers at Hospitality Badung Regency. In this paper" it discusses legal protection for the salary of contract employees and daily workers related to the employee's unfulfilled rights. According to the minister's decision No.100/MEN/IV/2004 concerning the implementation of certain time labor agreements that regulate contract workers and daily workers must obtain economic, social and protection of the technical. One of the legal protection of concern is legal protection for the salaries. The method used in the writing process of this journal is empirical legal research, research with interviews or research is directly into the field to obtain fact for this journal. This type of approach used in this study is the Statue Approach and Analytical And Conceptual Approach. The results of this study are the implementation of legal regulations relating to the legal protection of minimum salaries for contract employees and daily workers, has not been implemented optimally, especially with unpaid leave rights. legal sanctions for hotel companies that do not apply minimum salaries for contract employees and daily workers are prosecution by filing claims for industrial relations. This paper suggests that the company must protect the law and the rights of contract employees and daily workers. Companies that have contract employees and daily workers must provide information on their rights and obligations.
\end{abstract}

Keywords: Legal Protection, Contract Employees, Daily workers

\title{
I. PENDAHULUAN
}

\subsection{Latar Belakang}

Berbagai perkembangan perhotelan di Kabupaten Badung mempengaruhi pola produksi dan distribusi masyarakat, hal ini membawakan dampak berbagai positif ataupun negatif pada 
perekonomian di masyarakat dengan kaitannya dengan kenaikan kebutuhan hidup masyarakat. Berbagai perusahaan menawarkan pekerjaannya tetapi perusahaan harus patuh dan menjamin perlindungan hukum kepada karyawannya seperti membayar upah sesuai dengan ketentuan yang berlaku sebagai kewajiban para pengusaha. Tenaga kerja baik karyawan tetap maupun karyawan kontrak hendaknya mendapat perlindungan kesejahteraan yang merata. Salah satu perlindungan hukum yang menjadi perhatian adalah perlindungan hukum terhadap upah karyawan kontrak. Perusahaan dilarang membayar upah kepada pekerja atau buruh dibawah Upah Minimum Regional ( UMR ) yang diatur oleh Undang -Undang No. 13 Tahun 2003 Tentang Ketenagakerjaan atau yang disebut undang-undang ketenagakerjaan. Sistem pekerja kontrak, terdapat sistem kontrak harian yang sering digunakan pada industri perhotelan di Kabupaten Badung yaitu sistem kerja pekerja harian. Kontrak kerja pekerja harian merupakan pekerja kontrak yang dibayarkan harian per kedatangan. Kontrak kerja pekerja harian kerap digunakan pada industri perhotelan karena memiliki tingkat efisiensi anggaran yang baik bagi pihak manajemen. Sebagai contoh pihak manajemen suatu hotel akan memiliki acara yang diselenggarakan di hotel tersebut dengan skala besar, yang dimana memerlukan tambahan tenaga kerja bersifat sementara saja, momentum tersebut yang akan membuat pihak manajemen hotel mencari tenaga kerja pekerja harian untuk mengisi kekurangan tenaga tersebut. ${ }^{1}$ Kontrak kerja pekerja harian termasuk dalam perjanjian kerja waktu tertentu atau disingkat PKWT. Bagi para pekerja yang memiliki kontrak PKWT, maka pihak perusahaan hanya dapat melakukan perpanjangan satu kali

\footnotetext{
${ }^{1}$ Asri Wijayanti, 2010, Hukum Ketenagakerjaan Pasca Reformasi, h.45
} 
atau setara dengan kontrak kerja selama dua tahun. Hal tersebut diatur dalam Undang- Undang Ketenagakerjaan pasal 59 ayat (4) yang berbunyi : "Perjanjian kerja waktu tertentu yang didasarkan atas jangka waktu tertentu dapat diadakan untuk paling lama 2 (dua) tahun dan hanya boleh diperpanjang 1 (satu) kali untuk jangka waktu paling lama 1 (satu) tahun". Namun hal tersebut sering dilanggar oleh pihak perusahaan termasuk perusahaan perhotelan. Selain itu menurut Keputusan Menteri Tenaga Kerja dan Transmigrasi No. KEP.100/MEN/VI/2004 tentang Pelaksanaan Perjanjian Kerja Waktu Tertentu, pekerja harian hanya boleh bekerja selama 20 hari.

Permasalahan yang terjadi pada industri perhotelan tersebut menyebabkan para pekerja dengan kontrak kerja pekerja harian kurang memiliki perlindungan hukum terutama perihal perlindungan hukum terhadap upah yang diberikan. Salah satu hotel di kabupaten Badung yang menggunakan sistem pekerja kontrak pekerja harian adalah Legian Beach Hotel Bali. Legian Beach Hotel Bali adalah salah satu hotel yang paling senior di Bali terletak di Jl. Melasti No 1, Legian, Bali. Menerapkan sistem pekerja kontrak pekerja harian sejak tahun 2004, dimana pada saat itu pemerintahan memberikan izin bagi perusahaan untuk menggunakan perjanjian kerja waktu tertentu seperti outsourcing dan pekerja harian. Pada awalnya menggunakan tenaga kerja pekerja harian hanya pada saat-saat diperlukan seperti saat sedang mengadakan acara perayaan tahun baru. Namun seiring berjalannya waktu, mulai menggunakan sistem tenaga kerja pekerja harian kepada beberapa karyawan baru yang dikontrak dalam jangka waktu satu tahun.

Berdasarkan pemaparan dari latar belakang masalah diatas, maka terkait dengan artikel ilmiah yang berjudul : "Perlindungan 


\section{Hukum Pekerja Kontrak dan Pekerja harian Di Perhotelan Kabupaten Badung"}

Mengangkat dua rumusan masalah sebagai berikut :

a. Bagaimanakah penerapan peraturan dalam rangka perlindungan hukum terhadap pekerja kontrak dan pekerja harian?

b. Bagaimanakah pengaturan sanksi hukum bagi perusahaan Hotel yang tidak menerapkan upah minimum terhadap pekerja kontrak dan pekerja harian?

\subsection{Tujuan Penelitian}

Dari pembahasan latar belakang diatas, maka tujuan dilakukannya penelitian ini adalah untuk mengehtahui lebih jauh bagaimana peraturan tentang perlindungan pekerja kontrak dan pekerja harian dan memahami tentang sanksi bagi perusahaan yang tidak menerapkan upah minimum terhadap pekerja kontrak dan pekerja harian.

\section{ISI MAKALAH}

\subsection{Metode Penelitian}

Metode penelitian adalah cara-cara berpikir dan berbuat yang dipersiapkan dengan baik untuk mengadakan penelitian dan guna mencapai tujuan penelitian. ${ }^{2}$ Penelitian ini menggunakan penelitian hukum empiris yaitu suatu penelitian yang dilakukan dengan wawancara atau penelitian dengan secara langsung terjun kelapangan guna untuk mendapatkan kebenaran yang akurat.

\subsection{Hasil Dan Analisis}

\subsubsection{Pengaturan Perlindungan Hukum Pekerja Kontrak Dan Pekerja Harian}

Sistem pengupahan bagi pekerja kontrak dan pekerja harian harus dilandasi oleh landasan hukum yang berlaku. Salah satu

${ }^{2}$ Kartini Kartono, 2015 Metode Pembuatan kertas Kerja atau Skripsi Ilmu Hukum, Mandar Maju, Bandung, h.58 
hal yang harus diperhatikan adalah syarat dari isi perjanjian kontrak kerja bagi para pekerja tersebut. Pekerja/buruh sebagai warga Negara mempunyai persamaan kedudukan dalam hukum hak untuk mendapatkan pekerjaan dan penghidupan yang layak, mengeluarkan pendapat, berkumpul dalam suatu organisasi, serta mendirikan dan menjadi anggota serikat pekerja/serikat buruh. ${ }^{3}$

Pasal 52 ayat 1 Undang-undang Ketenagakerjaan juga menegaskan bahwa perjanjian kerja dibuat atas dasar kesepakatan kedua belah pihak, kemampuan atau kecakapan melakukan perbuatan hukum, adanya pekerjaan yang diperjanjikan dan pekerjaan yang diperjanjikan tidak bertentangan dengan ketertiban umum, kesusilaan, dan peraturan perundang undangan yang berlaku. Sistem pengupahan pekerja kontrak akan mengacu kepada jenis perjanjian pekerja atau para pekerja itu sendiri. Salah satu permasalahan hukum yang terkait dengan penerapan pekerja kontrak adalah bagaimana hubungan hukum antara karyawan kontrak atau karyawan pekerja harian dan perusahaan pengguna jasa tenaga kerja dan kemudian bagaimana mekanisme penyelesaian sengketa bila adanya karyawan kontrak atau pekerja harian yang melanggar aturan kerja pada di lokasi perusahaan pemberi kerja. ${ }^{4}$ Hubungan kerja yang terjadi adalah hubungan kerja antara pekerja kontrak atau pekerja harian dengan perusahaan pekerja harian atau perusahan penyedia jasa tenaga kerja, sehingga seharusnya karyawan pekerja harian menggunakan peraturan perusahaan pekerja harian, bukan peraturan perusahaan pengguna jasa pekerja. ${ }^{5}$

3 I Made Udiana, 2016, Kedudukan dan Kewenangan Pengadilan Hubungan Industrial, Udayana University Press, Denpasar. h. 44.

${ }^{4}$ Jehani, Libertus, 2008, Hak-Hak Karyawan Kontrak, Penerbit Forum Sahabat, Jakarta, h.20

${ }^{5}$ Mathis Canny, 2010, Manajemen Personalia dan Sumber Daya Manusia, Penerbit Elex Media, Jakarta, h. 36 
Karyawan pekerja harian atau pekerja kontrak di perusahaan tentu sewajarnya secara aturan dan disiplin kerja harus mengikuti ketentuan yang berlaku pada perusahaan pengguna pekerja harian tersebut, agar terciptanya hubungan kerja yang harmonis dalam suatu perusahaan. Apabila terjadi suatu perselisihan terhadap perburuhan penyelesaiannya adalah antara karyawan pekerja harian dengan perusahaan pekerja harian. Pekerja harian di Indoensia memiliki hak dan kewajiban, baik pekerja tetap maupun pekerja harian. Salah satu hak utama dari pekerja pekerja harian adalah mendapatkan upah yang sesuai dengan ketentuan Upah Minimum Kabupaten (UMK). Berdasarkan penjelasan dari perlindungan hukum diatas, dapat disimpulkan bahwa hak dari para pekerja atau pekerja harian harus tetap dipertahankan dan diperhatikan. Salah satu hak paling penting dari pekerja harian atau para pekerja adalah upahnya. 6

Perihal pelaksanaan hak pekerja mengenai upah, dilakukan wawancara dengan Bapak Gunarta sebagai Human Resources Manager wawancara pada tanggal 3 Januari 2019 menyatakan bahwa. Sejauh ini pemberian hak-hak pekerja kontrak harian lepas sudah baik, seperti nilai pemberian kompensasi finansial yang sudah memenuhi UMK Badung yaitu berkisar 2,5 juta rupiah jika pekerja harian lepas tersebut bekerja penuh selama 26 hari kerja. Jika karyawan tersebut mengambil hak cuti, maka pihak manajemen hanya akan membayarkan kompensasi sesuai dengan hari bekerja dari pekerja kontrak, pekerja harian tersebut. Kemudian waktu kerja delapan jam/hari, dengan jam kerja mulai pukul 08.00 WITA-16.00 WITA, dengan waktu istirahat selama 1 jam per hari. Selain itu pekerja harian lepas mendapatkan tunjangan makan sebesar 15.000 per harinya dan tunjangan

6 Harianto, Aries, 2016, Hukum Ketenagakerjaan, Makna Kesusilaan dalam Perjanjian Kerja, Laksbang Pressindo, Surabaya 
transportasi sebesar 10.000 per harinya. Dan jika pekerja harian lepas tidak enak badan atau sakit sudah tersedia fasilitas klinik yang tersedia.

Sistem pengupahan bagi pekerja kontrak, pekerja harian harus dilandasi oleh landasan hukum yang berlaku. Bentuk perlindungan upah itu berupa pengaturan tentang upah dan pengupahan yang diatur dalam Undang Undang Ketenagakerjaan. Penetapan upah minimum, upah kerja lembur, upah tidak masuk kerja karena berhalangan, upah tidak masuk kerja karena melakukan kegiatan lain diluar pekerjaannya, upah menjalankan hak dan waktu istirahat kerjanya, Berdasarkan wawancara dengan Bapak Gus Dedi selaku karyawan pekerja harian di hotel pada tanggal 19 Desember 2018, disebutkan bahwa pemberian upah terhadap pekerja kontrak pekerja harian seperti saya memang sudah sesuai dengan Upah Minimum Kabupaten Badung tahun 2018 sebesar Rp. 2.499.580, sedangkan upah bersih saya terima adalah sebesar Rp. 2.600.000, setiap bulannya selama 26 hari kerja. Pendapatan pekerja harian di hotel adalah sebesar Rp. 100.000 per hari, dimana satu bulan dapat bekerja. Namun jika saya mengambil hari cuti lebih dari dua hari dalam bulan tersebut, pendapatan saya akan berkurang dan gaji bersih yang saya terima akan berada di bawah UMK Kabupaten Badung. Berdasarkan hal tersebut dapat kita lihat bahwa salah satu faktor yang menyebabkan tidak terlaksananya pembayaran upah minimum terhadap pekerja kontrak pekerja harian adalah aturan perusahaan mengenai permasalahan cuti. Jika pekerja pekerja harian bekerja kurang dari 26 hari, maka pekerja tersebut akan mendapatkan upah kurang dari ketetapan UMR di Kabupaten Badung. Aturan perusahaan mengenai hak pekerja bagi pekerja pekerja harian diatur dalam peraturan bersama dan dicantumkan 
pada kontrak kerja pekerja harian. Perusahan wajib memberikan waktu istirahat dan cuti yang dimana waktu istirahat dan cuti sangat penting bagi pekerja, karena istrahat dapat mengembalikan kesegaran para pekerja yang telah melakukan kegiatan dalam bekerja. Adapun waktu istirahat dan waktu cuti lainnya antara lain cuti tahunan, cuti hamil dan keguguran untuk pekerja perempuan. Maka kewajiban pengusaha membayar upah terhadap pekerja yang telah melaksanakan kewajibannya dalam bekerja, wajib memberikan cuti terhadap pekerja kontrak dan pekerja harian. 7

\subsubsection{Pengaturan sanksi hukum bagi perusahaan yang tidak menerapkan upah minimum terhadap pekerja kontrak dan pekerja harian}

Pembentukan sanksi atau hukuman pada dasarnya terdapat upaya preventif dan represif didalamnya. Sanksi atau hukuman sebagai upaya preventif dijalankan guna memberi rasa takut kepada seseorang atau pengusahaan untuk melakukan pelanggaran terhadap hukum sedangkan upaya represif dijalankan guna membalas perbuatan orang yang melakukan pelanggaran hukum. 8 Pekerja wajib menjalankan tugas yang harus dikerjakan sehingga ia berhak atas upah dari hasil pekerjaannya. Pengusaha wajib membayarkan upah agar mendapatkan hak berupa tenaga dari para pekerja. Artinya, pengusaha tidak boleh dengan sewenang-wenang tidak atau telat

${ }^{7}$ Fitriani, D. (2015). Penjabaran hak tenaga kerja perempuan atas upah dan waktu kerja dalam peraturan perusahaan dan perjanjian kerja. Jurnal Magister Hukum Udayana (Udayana Master Law Journal), 4(2). https://ojs.unud.ac.id/index.php/jmhu/article/view/17542

${ }^{8}$ Vijayantera, I. (2016). Pengaturan tunjangan hari raya keagamaan sebagai hak pekerja setelah diterbitkan peraturan menteri tenaga kerja nomor 6 tahun 2016. Kertha Patrika, 38(2) https://ojs.unud.ac.id/index.php/kerthapatrika/article/view/30091 
dalam membayarkan upah pekerja. ${ }^{9}$ Upaya perlindungan hukum bagi pekerja tentang upah minimum juga sebagai pengaman agar upah tidak jatuh merosot sampai pada level terendah. Pada prinsipnya pengusahaan tidak semestinya memberikan upah dibawah ketentuan upah minimum kepada pekerja. Tetapi kenyataannya pengusahaan memberi upah tidak sesuai dengan ketentuan upah minimum. Upaya hukum yang dapat dilakukan oleh pekerja dengan menggunakan proses penyelesaian perselisihan hubungan industrial dengan cara melakukan perundingan bipartit, antara pekerja dengan pengusahaan secara musyawarah untuk mencapai mufakat. Dan jika satu bulan tidak tercapai kesepakatan, upaya selanjutnya adalah perundingan tripartit yang melibatkan dinas ketenagakerjaan dan transmigrasi sebagai penengah untuk mencapai kesepakatan antara pekerja dan pengusahaan. Apabila perundingan tripartit tetap tidak mencapai kesepakatan maka pekerja dapat mengajukan perselisihan kepada pengadilan hubungan industrial.

Berdasarkan Pasal 90 ayat (2) UU Ketenagakerjaan menyebutkan penangguhan pelaksanaan upah minimum bagi perusahaan yang tidak mampu dimaksudkan untuk membebaskan perusahaan yang bersangkutan melaksanakan upah minimum yang berlaku dalam kurun waktu tertentu. Apabila penangguhan tersebut berakhir maka perusahaan yang bersangkutan wajib melaksanakan upah minimum yang berlaku

${ }^{9}$ Gusti Ayu Inten Ardianti Dewi, (2017). Pelaksanaan Perjanjian Kerja Waktu Tertentu Terkait Fungsi Pengawasan Dinas Tenaga Kerja Transmigrasi Dan Sosial Di Pt Sarana Arga Gemeh Amerta Denpasar, Jurnal Hukum Bisnis Fakultas Hukum Universitas Udayana

https://ojs.unud.ac.id/index.php/kerthasemaya/article/view/37662 
pada saat itu tetapi tidak wajib membayar pemenuhan ketentuan upah minimum yang berlaku pada waktu diberikan penangguhan. Pengusaha dilarang memberikan upah di bawah ketentuan Upah Minimum. Pekerja juga dapat menempuh upaya hukum yakni dengan melaporkan ke pihak kepolisian. Ancaman hukum bagi pengusaha yang membayar pekerjanya di bawah upah minimum adalah pidana penjara paling singkat satu tahun dan paling lama empat tahun dan/atau denda paling sedikit Rp 100 juta dan paling banyak Rp 400 juta. Pekerja wajib menjalankan tugas yang harus dikerjakan sehingga ia berhak atas upah dari hasil pekerjaannya. Pengusaha wajib membayarkan upah agar mendapatkan hak berupa tenaga dari para pekerja. Artinya, pengusaha tidak boleh dengan sewenang-wenang tidak atau telat dalam membayarkan upah pekerja.

Apabila pengusaha melakukan pelanggaran karyawan dapat melaporkan kepada pengawas ketenagakerjaan, yang mengatur pengawasan ketenagakerjaan pada pemerintah provinsi dan pemerintah kabupaten/kota wajib menyampaikan laporan pelaksanaan pengawasan ketenagakerjaan kepada Menteri dan pengusaha tidak boleh menurunkan gaji atau upah secara sepihak tanpa pemberitahuan kepada karyawan. Hal ini didasarkan pada perjanjian upah yang tidak boleh dilanggar oleh kedua belah pihak. Dalam pengaturannya pengusaha tidak dibenarkan untuk menurunkan gaji karyawan secara sepihak karena perjanjian merupakan undang-undang bagi para pihak yang telah bersepakat artinya ketika sudah ada perjanjian bersama antara perusahaan dengan karyawan, maka para pihak tidak boleh tanpa 
sepengetahuan pihak lainnya untuk mengubah gaji yang tidak sesuai dengan perjanjian. ${ }^{10}$

\section{PENUTUP}

\subsection{Kesimpulan}

Berdasarkan pembahasan diatas, mak dapat disimpulkan sebagai berikut:

1. Pelaksanaan ketentuan hukum yang berkaitan dengan perlindungan hukum upah minimum bagi pekerja kontrak dan pekerja harian belum terlaksana secara maksimal khususnya yang berkaitan dengan hak cuti yang tidak dibayarkan secara penuh.

2. Pengaturan sanksi hukum bagi perusahaan perhotelan yang tidak menerapkan upah minimum terhadap pekerja kontrak dan pekerja harian adalah penuntutan dari pihak karyawan seperti pengajuan gugatan hubungan industrial dan ancaman pidana bagi pengusaha yang membayar upah pekerjanya di bawah upah minimum adalah pidana penjara paling singkat satu tahun dan paling lama empat tahun dan/atau denda paling sedikit Rp 100 juta dan paling banyak Rp 400 juta.

\subsection{Saran}

Adapun beberapa saran terkait permasalahan antara lain:

1. Hendaknya perusahaan yang mempekerjakan pekerja kontrak dan pekerja harian lebih meningkatkan perlindungan

10 Eka Prasetya Purnomo, (2016). Implementasi Perlindungan Hukum Terhadap Kecelakaan Kerja Bagi Pekerja Mini Market (Studi Kasus: Indomaret Kebo Iwa Denpasar), Jurnal Hukum Bisnis Fakultas Hukum Universitas Udayana https://ojs.unud.ac.id/index.php/kerthasemaya/article/view/42337 
hukumnya bagi karyawan pekerja kontrak dan pekerja harian termasuk pemenuhan hak cutinya.

2. Diharapkan perusahaan yang memperkerjakan pekerja kontrak dan pekerja harian secara bersikenambungan melakukan sosialisasi kepada karyawan pekerja kontrak dan pekerja harian berkaitan dengan hak-hak dan kewajibannya.

\section{DAFTAR PUSTAKA}

\section{BUKU-BUKU :}

Asri Wijayanti, 2010, Hukum Ketenagakerjaan Pasca Reformasi

Harianto, Aries, 2016, Hukum Ketenagakerjaan, Makna Kesusilaan dalam Perjanjian Kerja, Laksbang Pressindo, Surabaya

I Made Udiana, 2016, Kedudukan dan Kewenangan Pengadilan Hubungan Industrial, Udayana University Press, Denpasar

Jehani, Libertus, 2008, Hak-Hak Karyawan Kontrak, Penerbit Forum Sahabat, Jakarta

Kartini Kartono, 2015, Metode Pembuatan kertas Kerja atau Skripsi Ilmu Hukum, Mandar Maju, Bandung

Mathis Canny, 2010, Manajemen Personalia dan Sumber Daya Manusia, Penerbit Elex Media, Jakarta

\section{JURNAL :}

Fitriani, D. (2015). Penjabaran hak tenaga kerja perempuan atas upah dan waktu kerja dalam peraturan perusahaan dan perjanjian kerja, Jurnal Magister Hukum Udayana (Udayana Master Law Journal), 4(2). 
https://ojs.unud.ac.id/index.php/jmhu/article/view/17542

Vijayantera, I. (2016). Pengaturan tunjangan hari raya keagamaan sebagai hak pekerja setelah diterbitkan peraturan menteri tenaga kerja nomor 6 tahun 2016. Kertha Patrika, 38(2).

https://ojs.unud.ac.id/index.php/kerthapatrika/article/view $\not 30091$

Gusti Ayu Inten Ardianti Dewi, (2017). Pelaksanaan Perjanjian Kerja Waktu Tertentu Terkait Fungsi Pengawasan Dinas Tenaga Kerja Transmigrasi Dan Sosial Di Pt Sarana Arga Gemeh Amerta Denpasar, Jurnal Hukum Bisnis Fakultas Hukum Universitas Udayana

https://ojs.unud.ac.id/index.php/kerthasemaya/article/view $\lcm{37662}$

Eka Prasetya Purnomo, (2016). Implementasi Perlindungan Hukum Terhadap Kecelakaan Kerja Bagi Pekerja Mini Market (Studi Kasus: Indomaret Kebo Iwa Denpasar), Jurnal Hukum Bisnis Fakultas Hukum Universitas Udayana

https://ojs.unud.ac.id/index.php/kerthasemaya/article/view $\lcm{42337}$

\section{PERATURAN PERUNDANG-UNDANGAN :}

Undang-Undang Republik Indonesia Nomor 13 Tahun 2003 Tentang Ketenagakerjaan, (Lembaran Negara Republik Indonesia Tahun 2003 Nomor 39)

Undang-Undang Republik Indonesia Nomor Nomor 2 Tahun 2004 Tentang Penyelesaian Perselisihan Hubungan Industrial, (Lembaran Negara Republik Indonesia Tahun 2004 Nomor 6) 
Keputusan Menteri Tenaga Kerja dan Transmigrasi Nomor: KEP.100/MEN/VI/2004 tentang Ketentuan Pelaksanaan Perjanjian Kerja Waktu Tertentu 